\title{
DOLOR Y ESPERANZA \\ EL PASADO DICTATORIAL CHAQUEÑO Y LA FUNCIÓN SOCIAL DE LOS MURALES
}

JARA, Rebeca E.; ZEITLER, Tomás E.

Adscripta al Instituto Interdisciplinario de Investigación en

Diseño, Facultad de Arquitectura y Urbanismo (UNNE)

Docente investigador del Departamento de Historia,

Facultad de Humanidades (UNNE).

rebecajaradg@gmail.com

\section{PALABRAS CLAUE}

Memoria; identidad; dictadura.

RESUMEN

El presente trabajo analiza el mural "Argentina: dolor y esperanza" (1986, Amanda Mayor de Piérola, Salón de Actos de la Universidad Nacional del Nordeste, Resistencia) a partir de variables propias de los estudios de memoria y el análisis de la imagen. Explica las características gráficas y contextuales de este mural referido al último pasado dictatorial en el Chaco en función de las formas en que los grupos generan conciencia identitaria por medio del arte mural. A partir de este análisis, se establece la contribución del mural en la construcción de una memoria colectiva sobre el pasado dictatorial.

\section{KEYWORDS}

Memory, identity, dictatorship.

ABSTRACT

The present work analyzes the mural "Argentina: pain and hope" (1986, Amanda Mayor de Piérola, Assembly Hall of the Universidad Nacional del Nordeste, Resistencia) based on own variables of memory studies and image analysis. It explains the graphic and contextual characteristics of this mural referred to the last dictatorial past in Chaco, based on the ways in which groups generate identity awareness through mural art. From this analysis, the contribution of the mural in the construction of a collective memory on the dictatorial past is established. 


\section{OBJETIUOS}

- Determinar las características gráficas y contextuales del mural "Argentina: dolor y esperanza" referido al último pasado dictatorial en el Chaco. - Caracterizar esta obra en sus aspectos gráficos (estilo, morfología, color, composición, simbología).

- Comprender las formas en que los grupos detentadores de memoria generan conciencia identitaria y mantienen viva su identidad por medio del arte mural.

- Establecer la contribución de este mural en la construcción de una memoria colectiva en torno a ese pasado dictatorial.

\section{INTRODUCCIÓN}

El análisis de los usos y funciones sociales del mural requiere una mirada multidisciplinar, con aportes conceptuales y metodológicos del arte, la historia, la estética, la sociología del arte, la arquitectura y el diseño gráfico. Por eso, nuestra indagación propone comprender estos objetos visuales producidos bajo la influencia de mentalidades colectivas, convicciones políticas, concepciones artísticas, coyunturas sociales y demandas del público.

Los murales pertenecen al "arte social" (siguiendo la clasificación de Pierre Bourdieu) que por medio de símbolos y signos interactúa con la sociedad en torno a problemas culturales, educativos, políticos e ideológicos. Tienen una función social muy activa: proponen contra-discursos políticos, expresan luchas por la memoria del pasado reciente y colectivo, defienden los derechos humanos, fortalecen la historia local-regional y la identidad social.

El fenómeno del mural ha sido abordado desde diversas perspectivas (historia del arte, sociología, estética y teoría del arte), enfocadas en las relaciones de esta pintura con el contexto histórico social o las características de los estilos artísticos, produciendo no solo estudios sobre maneras de hacer artísticas, sino también catálogos fotográficos. Sin embargo, faltan estudios más profundos sobre el fenómeno muralístico, que además de analizar las anteriores cuestiones avancen sobre las relaciones entre imagen e identidad, imagen y memoria, imagen y comunicación. ${ }^{1}$

La actividad muralista ha irrumpido con fuerza en las ciudades de nuestro país desde fines del siglo XX, modificando los espacios públicos. Han participado de esta actividad grupos ligados al campo social, político y artístico. Adquiere así una función no solo decorativa, ilustrativa o narrativa, sino también comunicativa, en tanto es utilizada como agente de cambio, como medio de difusión colectivo de la pintura.

Además, el mural es la representación de una voz consciente, que puede ser analizada como una proposición de enunciados relaciona- dos con una identidad social y una memoria histórica. ${ }^{2}$ Entendemos a la representación como la exhibición de una presencia y ausencia: "el instrumento de un conocimiento mediato que hace ver un objeto ausente al sustituirlo por una imagen capaz de volverlo a la memoria y de pintarlo tal cual es" (Chartier, 2002, p. 57). Y a la memoria histórica como aquella que toma del pasado lo que le sirve al presente y el futuro de una comunidad; en este sentido, la memoria refuerza la identidad y el sentido de pertenencia y permanencia temporal y espacial (Le Goff, 1991, p.181).

La memoria colectiva, entendida como un entretejido de memorias individuales enmarcadas socialmente en un conjunto de tradiciones, se expresa por medio de códigos culturales compartidos. Por eso un estudio de los murales referidos al pasado dictatorial en el Chaco exige la comprensión de sus significantes con relación con la memoria colectiva (Jelin, 2002, p. 22).

Las imágenes de los murales siempre dan cuenta de un proceso histórico, y tienden a forman parte de los espacios en donde se desenvuelven las luchas, como vehículos que contribuyen a conformar la identidad colectiva. Este tipo de arte social va más allá de la propuesta artística o estética y se expresa como una alternativa de cambio social, de intervención política (Revale, 2009, p. 32). Por esto, se afirma también que los murales producidos en tiempos de represión -o posteriores pero referidos a ese pasado traumático- buscan dar cuenta de las prácticas identitarias: son parte de un conjunto de estrategias por medio de las cuales se busca sostener la lucha - política, social, civil- contra las relaciones de explotación y dominación (Di Luca, 2009, p. 48) 
Por todo lo anterior, sostenemos que los murales tienen una función social muy activa: proponen contra-discursos políticos, expresan luchas por la memoria del pasado reciente y colectivo, defienden los derechos humanos, fortalecen la historia local-regional y la identidad social. ${ }^{3}$

Proponemos entonces una serie de preguntas que permitan comprender y analizar los murales como fenómeno artístico y social: ¿Qué características gráficas tienen? ¿Qué puede verse en cada uno? ¿Por qué fueron creados? ¿Qué objetivos e historias esconden o manifiestan? ¿Qué ideas evoca la imagen? ¿Qué puntos de atracción tiene? ¿Cómo interactúa la imagen con el texto? ¿Cuál es el mensaje que se pretende dar? ¿Cómo se evidencia el contexto socio-histórico? ¿Cómo posibilitan las expresiones y estéticas del arte mural la reconstrucción de memorias? ¿De qué manera estas expresiones artísticas agencian formas de lo político y de usos de la esfera pública?

Existen interesantes estudios sobre murales realizados en distintos espacios académicos. El sociólogo Bill Rolston, por ejemplo, trabajó sobre las diversas muestras murales en Irlanda del Norte. J. Garí Clofent y Brassaí destacan con sus estudios sobre grafiti en Francia (ambos de 1993), al igual que los de Fernando Arias (1977), Federico Gan Bustos (1978), Vicente Comes (1988) y García Haczek (1995) respecto de grafitos y murales en España, o los de Vicente Josep Escartí (1989) y A. Petrucci (1996) para Italia. Sobre murales en EE. UU., las contribuciones de Craig Castleman (1982). En México, María Isabel Belausteguigoitia realizó a través de los murales contemporáneos un acercamiento a los grupos indígenas rebeldes, mien- tras que Laura Martínez Hernández lo hizo en relación con los murales callejeros como herramientas de resistencia política, además de los diversos trabajos de Cristina Híjar (2011, 2013, 2017). Otros abordajes se enfocaron en el rescate gráfico de algunos murales contemporáneos, como por ejemplo las obras de $\mathrm{Ni}$ cholas Ganz (2004) y de Luis Bou (2008). También encontramos una producción reciente de análisis de la imagen (grafiti, murales, etc.) con perspectiva latinoamericana, como por ejemplo los estudios de Alejandra Sandoval (2002), los de Corrales (2003) o los de Longoni sobre colectivos artísticos (2008). También la tesis de magíster en estudios latinoamericanos de Paula Alcatruz Riquelme, que propone un análisis comparativo de murales en Chile y Argentina entre fines del siglo $X X$ y principios del siglo XXI. En contextos nacionales tenemos, para el caso colombiano, el trabajo de Martha Herrera y Vladimir Playa (2011) y los anteriores de Silva Téllez (1988); para el caso chileno, los trabajos de Paula Alcatruz (2005), Eduardo Castillo Espinoza (2007), Palmer Rod (2008) y Natalia Pinochet Cobos (2009); para el caso boliviano, los del sociólogo Fernando Calderón (1991).

En Argentina, encontramos el estudio de Ana Vidal que desde el arte y la memoria colectiva indagó sobre las representaciones de la militancia política y la represión de la década del 70 en Bahía Blanca, entre 19952009. El Ministerio de Educación de la Nación Argentina también publicó la obra "Murales que hablan" para recuperar y analizar las acciones de política pública que fueron llevadas a cabo en el marco de los Centros de Actividades Juveniles en distintas provincias del país. Muy importante es la tesis, y demás trabajos publi- cados, de Verónica Capasso (2010 y 2011) sobre el muralismo en la ciudad de La Plata en la segunda mitad del siglo XX, contando como antecedentes sobre ese espacio las investigaciones de Di María, González y Ruiz (2005). Más recientemente, los aportes de Luis María Blasco (2015) en relación con murales en la Ciudad Autónoma de Buenos Aires.

Sobre Corrientes, tenemos los trabajos de Carlos Manzi (1997) y Aurora Arbelo de Mazzaro, que buscan rescatar y valorizar los murales correntinos como patrimonio cultural, junto a otros abordajes históricos sobre las artes plásticas en la provincia, como los de Almoznino (1985) y los de Marcelo Fernández (2003 y 2012), además de una Bitácora de Muros elaborada por Kura y Almeida (2004) por iniciativa de la Subsecretaría de Cultura y Turismo Municipal de Corrientes.

Para el Chaco, contamos con el análisis de Miryam Romagnoli (1992) sobre un mural de Pettoruti en Resistencia, los estudios realizados por Mariana Giordano sobre los murales de la UNNE (1993) y los murales chaqueños (1998), y en coautoría con Ramón Gutiérrez (2000) sobre la imagen urbana de Resistencia, y con Gabriel Romero (2013) sobre las artes visuales en Corrientes y Chaco, además de investigaciones históricas sobre la labor artística y cultural del Fogón de los Arrieros, en coautoría con Rodrigo Gutiérrez (1992) y con José E. Cantero (2015).

\footnotetext{
3. Muchos autores señalan también que el muralismo implica la ocupación, modificación y reclamo en escenarios no convencionales, lo que genera una red de comunicación de contenidos gráficos, tomas de postura política y demandas sociales.
} 


\section{RESULTADOS}

\section{"La Masacre de Margarita Belén": inscripción social y mural del recuerdo}

El día 11 de diciembre de 1976, el Comando de la VII Brigada del Ejército, a cargo del general Cristino Nicolaides, ordenó el traslado a la prisión de Formosa de un grupo de detenidos políticos alojados en la Alcaidía Policial y Prisión Regional del Norte $(U$. 7) de la ciudad de Resistencia (Chaco, Argentina) ${ }^{4}$ quienes estaban acusados de generar desórdenes entre la población penal. En ese traslado se sumaron otras personas que estaban detenidas en situación de clandestinidad y algunas cuya identidad se busca aún establecer. ${ }^{5}$

Los trasladados de la U. 7 fueron concentrados con otros presos en la alcaidía, donde fueron torturados hasta aproximadamente las 01: 30 horas del día 13 de diciembre de 1976. Aproximadamente a las 03: 30 horas del mismo día, los prisioneros fueron retirados por una comisión de militares en dos camiones, un Unimog y un Mercedes Benz pertenecientes a la Compañía de Comunicaciones 7 , y un vehículo policial conducido por el policía Alfredo Luis Chas. La columna se dirigió por la ruta $N^{\circ} 11$ en dirección a Formosa, y al llegar a las proximidades de Margarita Belén, en un camino lateral, a las 04: 30 horas aproximadamente, fueron ejecutados los detenidos y algunos de ellos permanecen aún desaparecidos. ${ }^{6}$
La investigación realizada por la Conadep (Comisión Nacional de Desaparición de Personas), y como además lo registra el Informe Final de la Comisión de DD. HH. de la Cámara de Diputados de la Provincia del Chaco, corroboran que Oscar Zucconi junto al gobernador Facundo Serrano y el jefe de policía provincial Wenceslao Ceniquel sobrevolaron días antes en helicóptero el lugar donde, el 13 de diciembre de 1976, fueron fusilados al menos veintidós presos políticos, bajo el justificativo de intento de fuga.

A pesar de la gravedad del hecho, durante los años de dictadura cívico-militar-eclesiástica y los primeros años de transición a la democracia, la inscripción social de los sucesos de la Masacre de Margarita Belén como recuerdo colectivo debió enfrentar la difícil etapa de lo que, en términos de Todorov, serían los efectos de la memoria amenazada. Durante las intervenciones militares de Oscar Zucconi (25 de marzo a 23 de abril de 1976), Antonio Serrano (23 de abril de 1976 a 29 de marzo de 1981) y José David Ruiz Palacios (29 de marzo de 1981 a 10 de diciembre de 1983), la coyuntura política no fue favorable para los grupos afectados y, además, las estrategias de conservación y defensa de una memoria colectiva aún estaban en proceso de gestación. Se impuso entonces, desde el poder político-militar, la "teoría del enfrentamiento" que luego sería resignificada con justificativos de desconocimiento u obediencia debida, amparados en el marco general de la "teoría de los dos demonios".
Desde 1983, a pesar de las diferencias partidarias a nivel nacional, donde se impuso el radicalismo con Alfonsín mientras que a nivel provincial el justicialismo ganó las elecciones con la candidatura de Florencio Tenev, ambos gobiernos de turno debieron enfrentar la difícil tarea de legitimar y consolidar una democracia débil, que resurgía tras una férrea dictadura desprestigiada por su derrota en Malvinas y acusada desde varios frentes por el ejercicio del terrorismo de Estado. A pesar de las indiferencias políticas, el nuevo contexto de libertad estimuló inmediatamente a familiares de víctimas, exdetenidos y defensores de los DD. HH. para organizar la conmemoración -en diciembre de 1983-de los sucesos que ahora comenzaban a ser representados como la "masacre" de Margarita Belén: la teoría del enfrentamiento cedía ante una nueva política de memoria, mientras los partidos políticos mantenían distancia de los reclamos y conmemoraciones, y el caso Margarita Belén adquiría relevancia nacional al ser incorporado por la Conadep y como caso 678 en la Causa 13 abierta contra la junta militar. Las nuevas condiciones parecían favorables, no solo para resignificar una memoria colectiva, sino también para avanzar en la búsqueda de la justicia. Los argumentos discursivos eran más que suficientes para impulsar políticas de memorias más firmes tendientes al esclarecimiento del caso.

Pero mientras la justicia se retrasaba entre indiferencia y demoras, en 1986 un grupo de estudiantes aunaron esfuerzos para la concreción de un mural recordatorio en el aula magna de la UNNE, en Resistencia. El encargo fue para la artista plástica Amanda Mayor de Piérola, madre de Fernando Piérola, uno de los estudiantes asesinados (desaparecido) en diciembre de 1976. El mural, titulado "Argentina: Dolor y Esperanza" (inaugurado el 15 de agosto de 1986), mostraba una escena desgarradora de tortura: el pecho acribillado de un joven dividía la escena que pretendía mostrar en cada uno de sus lados a las dos Argentinas: la del Dolor, como consecuencia de la

7. Al respecto véase el artículo de Franco (2014). 




Figura 1. Amanda Mayor de Piérola, Argentina: Dolor y Esperanza, 1986. Pintura sobre pared. Fotografía de Rebeca E. Jara (2018)

dictadura y las torturas, pero también la Esperanza expresada en el trabajo, la unión de las familias y los niños felices en las escuelas. La imagen se transformó pronto en motivo de discordia, puesto que la escena de tortura estaba siendo presenciada por un sacerdote, como expresión de una complicidad conocida por muchos, pero reconocida por pocos.

Los reclamos no tardaron en hacerse manifiestos, y los obispos de Corrientes y Resistencia, Antonio Rossi y Juan José Iriarte, presentaron un recurso de amparo que llevó a Norberto Giménez, juez federal de Resistencia, a emitir una resolución para borrarlo. Las autoridades católicas negaban cualquier implicación específica con el caso Margarita Belén, tanto como toda complicidad general en relación con el pasado dictatorial. El Consejo Superior de la UNNE, que ya había aprobado el boceto de la obra, finalmente cedió a la resolución del juez, pero como ningún artista se prestó a concretar la "corrección", no quedó más opción que taparlo burdamente con brocha. En 1988, Amanda restituyó la polémica imagen, aunque recién en 2004 por fallo del juez Skidelsky el mural fue oficialmente restaurado. Ese mismo año, Amanda fue decla- rada "Ciudadana llustre de la Provincia" por la Cámara de Diputados del Chaco.

\section{El mural "Argentina: Dolor y Esperanza": imágenes, signos, colores, mensajes}

Precisamente, este contexto sociopolítico evidencia la consideración de Roland Barthes (1992) de que el enfoque visual se determina por los intereses, las conformaciones culturales y la experiencia del observador. Por esto, debemos considerar al menos tres advertencias metodológicas respecto del análisis visual de murales:

1. No podemos presumir al mural como una representación verídica de una situación o hecho histórico, pues se ubica en un flujo de interpretaciones.

2. La imagen, al llegar a simple vista, ejerce un mayor poder sobre el observador que la escritura.

3. La temática de los murales tiende a buscar representar un problema social o político contingente, y su creación suele ser de carácter colectivo.

Es a partir de estas consideraciones que realizamos el siguiente análisis de la imagen. Si observamos la mitad superior de la pared de fondo del
Aula Magna de la UNNE (campus de la ciudad de Resistencia), apreciamos el gran mural de Amanda, "Argentina: dolor y Esperanza", que por sus propias dimensiones capta la atención de quienes ingresan al salón. El mural presenta diversos y complejos aspectos gráficos y estéticos a través de una megaimagen que pretende contar una historia, una realidad social traumática presente en la memoria colectiva del pueblo chaqueño, principalmente los sectores perseguidos durante la última dictadura militar.

Nos interesa analizar esta imagen tanto desde lo connotativo como de lo denotativo, reconociendo también que estos términos van ligados, en el sentido de que no existe uno sin el otro y es precisamente esta relación dialógica lo que, finalmente, otorga sentido profundo a la imagen. Como sabemos, los valores expresivos, comunicativos, emotivos y estéticos se dan a través del análisis connotativo de la imagen, mientras que lo evidente de la imagen y su lectura objetiva y descriptiva hace referencia a lo denotativo de aquella. A partir de esta consideración preliminar, podemos analizar la estructura de cada elemento, principalmente las imágenes y caligrafía ubicadas en la pintura. 




Figura 2. Amanda Mayor de Piérola, Argentina: Dolor y Esperanza, 1986. Pintura sobre pared. Fotografía de Rebeca E. Jara (2018)

En primer lugar, se puede apreciar que el mural está dividido en dos partes por un eje central, con un importante centro de interés que es el muchacho con las estacas clavadas en su torso desnudo. Esta imagen sirve para separar el "dolor" de la "esperanza", y permite a la artista plantear una antítesis entre las figuras representadas en el lado izquierdo del espectador (la Argentina del dolor) del lado derecho (la Argentina de la esperanza). En el lado izquierdo podemos observar distintas imágenes representativas de la temática abordada en el mural: un grupo de personas desnudas que están siendo sometidas de distintas maneras por grupos de soldados. Estas imágenes son reforzadas en la parte superior, en tanto que en la sección inferior se aprecia un grupo de mujeres protestando contra los soldados, contra el régimen del terror y sus abusos políticos e ideológicos.

En este lado del mural, una de las más emotivas imágenes se encuentra en la parte inferior, donde podemos visua- lizar primero a una persona en posición cenital con sus ojos vendados y aferrándose a la mano del muchacho. La sensación queda reforzada por un conjunto de huesos de los esqueletos humanos que han sido sacrificados en su lucha contra el régimen del terrorismo de Estado.

Si observamos la parte derecha del mural, encontramos contrastes importantes con el lado anteriormente analizado, dado que el artista a través de imágenes que evocan la familia, el trabajo, los niños en la escuela, el campo y los animales, quiere mostrar que aún hay esperanza de recuperar mejores condiciones de justicia y paz social.

Observando el mayor punto de interés del mural, que se delimita por el muchacho pintado en el centro, podemos ver cómo el artista utiliza colores análogos al tono natural de la piel humana (como rojo, anaranjado, amarillo). Si lo analizamos desde lo connotativo, podemos inferir que la imagen pretende generar la sensación de una persona que, aun estando viva, sufre el dolor de la tortura que queda expresada por las estacas clavadas en su pecho y por el gesto de sufrimiento de su rostro.

A su vez, se aprecia cómo la imagen presenta un eje horizontal a lo largo del mural, representado por una línea de mujeres pintadas en blanco y gris que van marchando, lo que aumenta la sensación de unidad y estabilidad del cuadro. Se observa que comienza en un monumento y termina con la imagen de un predio lleno de cruces que representan la muerte, reforzando con esto el sentimiento de dolor de aquellas madres que han perdido a sus hijos en este proceso de lucha.

Examinando el mural en su totalidad, vemos que predominan los colores fríos, especialmente en las escenas de fondo que dividen, mediante líneas curvas, las distintas imágenes. Estos colores refuerzan la sensación de tristeza, dolor y alejamiento en el espectador. Además, las distintas perspectivas de la imagen hacen que se pueda 
alcanzar efectivamente la intención de trasmitir distintos hechos a la vez: por un lado, el acontecimiento específico de la Masacre de Margarita Belén; por otro lado, la evocación general a los crímenes cometidos por la última dictadura militar en nuestro país.

Respecto de la frase escrita en el mural, podemos señalar que este tipo de caligrafía aumenta la identidad y personalidad del mural. Las únicas palabras plasmadas en el mural ("Margarita Belén, 15/12/76") son las que hacen alusión al suceso histórico específico señalado anteriormente, pues de lo contrario bien podríamos interpretar que el mural refiere a hechos generalizados propios del terrorismo de Estado.

Teniendo en cuenta todos estos aspectos podemos concluir, siguiendo los aportes del lingüista Roman Jakobson en torno a las funciones del lenguaje, que este mural cumple principalmente una función emotiva, dado que está centrado en el emisor con una finalidad sentimental y tiene por objeto transmitir sus emociones y estados de ánimo, pero además está reforzado por una función referencial que en este caso remite a un contexto socio-histórico provincial y nacional.

\section{CONCLUSIONES}

El análisis realizado nos permite establecer las siguientes conclusiones: -El mural "Argentina: dolor y esperanza" constituye un lugar de memoria que posibilitó la inscripción y preservación del recuerdo colectivo de grupos sociales específicos, ligados al último pasado dictatorial en el Chaco. - Las características gráficas de este mural (estilo, morfología, color, composición, simbología) guardan relación con los discursos y representaciones en torno al pasado traumático del período dictatorial, que los grupos emprendedores de memoria elaboraron y expresaron

Los murales, junto con otros tipos de representación gráfica, constituyen un soporte material a la memoria colectiva, y desde el retorno a la democracia se evidencia en el Chaco un fenómeno muralístico, referido al pasado traumático de la última dictadura militar. El análisis de la imagen de este mural de la ciudad de Resistencia nos ofrece un horizonte para reinterpretar los procesos históricos que fueron vividos y representados gráficamente. Por todo lo anterior, buscamos en este trabajo caracterizar estas obras en sus aspectos gráficos, pero también interpretar el sentido que los realizadores de mensajes les otorgaron a sus obras, para comprender su visión activa, además de reconocer el lugar que ocupan en las políticas de memoria y examinar las relaciones entre las características gráficas de los murales y los discursos y representaciones en torno al pasado dictatorial. Consideramos que este análisis contribuirá al estudio de las producciones estéticas locales y también a la comprensión del contexto en el cual, y por el cual, surgieron algunos de los murales de nuestro medio.

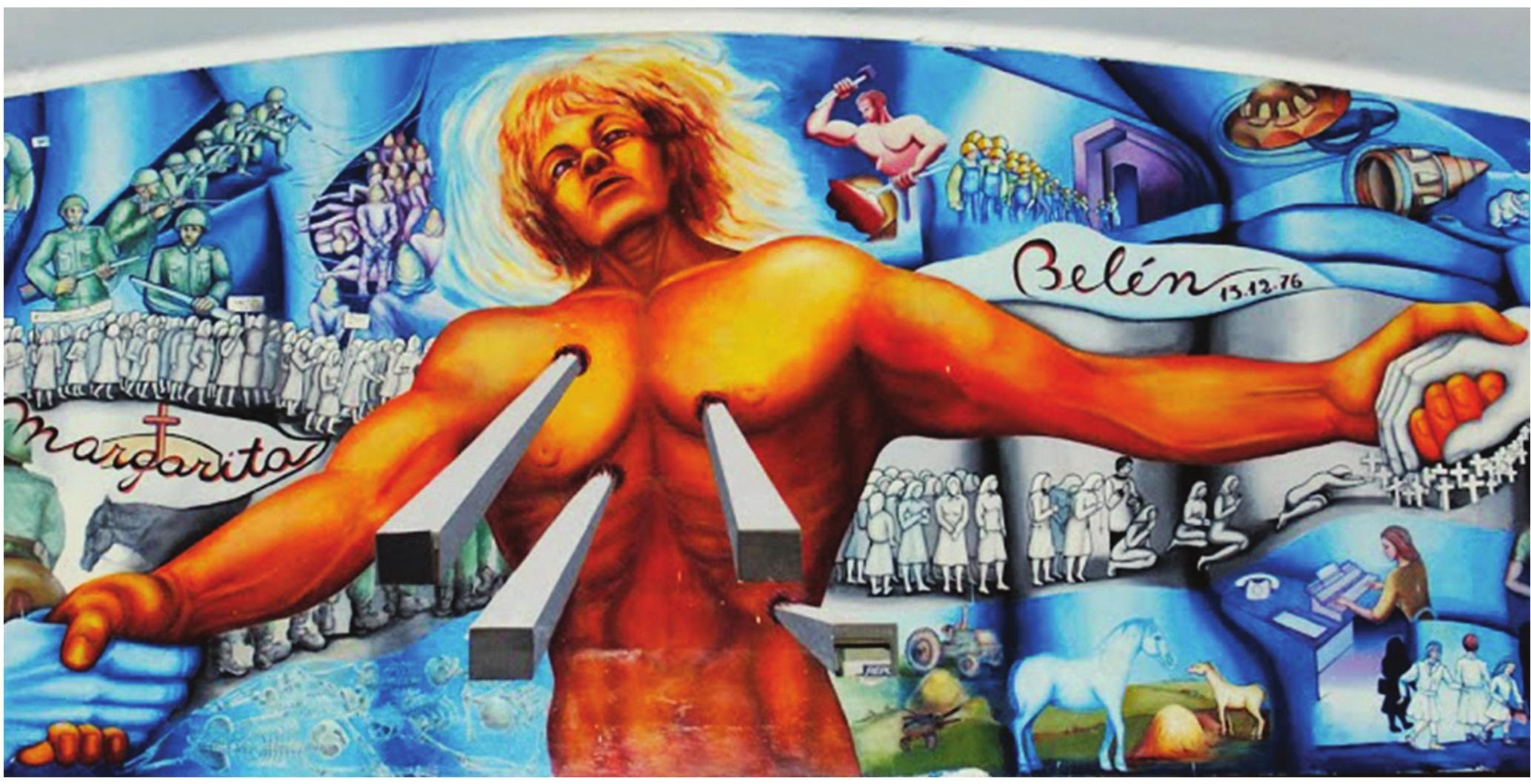

Figura 3. Amanda Mayor de Piérola, Argentina: Dolor y Esperanza, 1986. Pintura sobre pared. Fotografía de Rebeca E. Jara (2018) 


\section{REFERENCIAS}

\section{BIBLIOGRÉFICAS}

BARTHES, Roland (1992). La Cámara Lucida. Barcelona: Editorial Paidós. BOURDIEU, Pierre (2000). Intelectuales, política y poder. Buenos Aires: Eudeba.

CHARTIER, Roger (2002). El Mundo como representación. Historia cultural: entre práctica y representación. Barcelona: Gedisa.

DI LUCA, Fabiana (2009). "Frágiles y luminosos: trazos sobre la vida cotidiana". En Vespegnani, Florencia, Gráfica Política. Buenos Aires: Editorial el colectivo.

GANZ, Nicholas (2004). Graffiti: arte urbano de los cinco continentes. Barcelona: Editorial Gustavo Gili.

JELIN, Elizabeth (2002). Los trabajos de la memoria. Madrid: Siglo XXI.

LE GOFF, Jacques (1991). El orden de la memoria. España: Paidós.

FRANCO, Marina (2014). "La teoría de los dos demonios: un símbolo de la posdictadura en Argentina", Contracorriente, vol. 11, núm. 2, 2014, pp. 22-52.

GARAÑO, Santiago y PERTOT, Werner (2007). Detenidos-Aparecidos. Buenos Aires: Biblos.

REVALE, Natalia (2009). "Nuevas formas de expresión y de lucha". En Vespegnani, Florencia, Gráfica Política. Buenos Aires: Editorial el colectivo. 